\title{
Investigation into an unusual increase of human cases of Salmonella Goldcoast infection in Hungary in 2009
}

J K Horváth (horvath.krisztina@oth.antsz.hu) ${ }^{1}$, M Mengel ${ }^{2,3}$, K Krisztalovics ${ }^{1}$, N Nogrady ${ }^{1}$, J Pászti ${ }^{1}$, A Lenglet ${ }^{4}$, J Takkinen ${ }^{4}$

1. National Center for Epidemiology, Budapest, Hungary

2. National Centre for Epidemiology, Madrid, Spain

3. European Programme for Intervention Epidemiology Training (EPIET), European Centre for Disease Prevention and Control (ECDC), Stockholm, Sweden

4. European Centre for Disease Prevention and Control (ECDC), Stockholm, Sweden

Citation style for this article:

Horváth JK, Mengel M, Krisztalovics K, Nogrady N, Pászti J, Lenglet A, Takkinen J. Investigation into an unusual increase of human cases of Salmonella Goldcoast infection in Hungary in 2009. Euro Surveill. 2013;18(11): pii=20422. Available online: http://www.eurosurveillance.org/ViewArticle.aspx?Articleld=20422

We describe the outbreak investigation associated with an unusual increase in Salmonella Goldcoast cases in Hungary observed in autumn 2009, which included descriptive and analytical epidemiological studies and microbiological and veterinary investigations. Sixty cases were identified between 1 January 2009 and 1 March 2010, 50 of them from late July 2009 to January 2010. Of $50 \mathrm{~S}$. Goldcoast isolates, 44 showed an indistinguishable pulsed-field gel electrophoresis profile. We conducted a matched case-control study that indicated a statistically significant association between $S$. Goldcoast infection and the consumption of pork cheese. The majority of cases (seven of nine) reporting consumption of this product belonged to a single family cluster. After removing six cases of this cluster, pork cheese still showed an elevated but non-significant risk for being a case in the univariable analysis (Mantel-Haenszel odds ratio (MH OR): 3.87 , $95 \%$ confidence interval $(\mathrm{Cl}): 0.38-39.47)$. A single $S$. Goldcoast isolate was identified during routine veterinary surveillance activities in 2009 in minced beef from a butcher's shop, originating from an abattoir where also pigs were slaughtered. We conclude that the outbreak was probably due to multiple sources of contaminated meat, probably pork, released on the market over a period of several months in 2009.

\section{Introduction}

Salmonella enterica serovar Goldcoast is rarely reported to cause outbreaks in the European Union (EU). Previous outbreaks have been reported in the United Kingdom and Germany and were found to be associated with the consumption of French paté, watercress, cheddar cheese and raw fermented sausage [1-4]. In a multi-country outbreak due to Salmonella Goldcoast in 2004, the majority of reported cases had travelled to Mallorca in Spain in the week before their disease onset, although no common source of exposure could be identified [5-7].

In Hungary, between 2004 and 2008, an average of 12 cases of $S$. Goldcoast was reported annually (ranging from three in 2007 to 21 in 2005). An unusual increase to 28 cases of diarrhoea due to $S$. Goldcoast was observed in Hungary between late July and September 2009. In order to verify whether this occurred only in Hungary, the Hungarian National Center for Epidemiology (NCE) sent an urgent inquiry to the European Food and Waterborne Diseases and Zoonoses (FWD) network on 7 October 2009. Italy responded that they had observed a similar unusual increase in S. Goldcoast reports in 2009.

In order to understand the scale of the outbreak, to compare S. Goldcoast isolates and to identify possible risk factors for these infections, we embarked on a microbiological and epidemiological investigation of all $S$. Goldcoast cases identified in Hungary between 1 January 2009 and 1 March 2010. The investigation conducted by our Italian counterparts is described in this edition of the journal [8].

\section{Methods}

\section{Descriptive epidemiology}

We defined a case as a person resident in Hungary with a positive laboratory diagnosis for $S$. Goldcoast. We included all cases of infection with $S$. Goldcoast registered in the national database of notifiable diseases between 1 January 2009 and 1 March 2010.

Human isolates of S. Goldcoast from cases in 2009 were sent to the National Reference Laboratory for Salmonella at the NCE for confirmation. At the Department of Phage Typing and Molecular Epidemiology, pulsed-field gel electrophoresis (PFGE) and antibiotic resistance testing were performed using streptomycin, chloramphenicol, tetracycline, kanamycin, ampicillin, gentamicin, nalidixic acid, ciprofloxacin, cefotaxime, sulphonamide, sulphamethoxazole/trimethoprim as agreed by the EU surveillance panel [9]. The PFGE analysis was performed according to the PulseNet standardised protocol using $X b a l$ DNA digestion and $50 \mu \mathrm{M}$ thiourea was added to the running buffer $[10,11]$. Salmonella enterica serotype Braenderup H9812 strain was used as the molecular size marker [12]. DNA profiles differing by 
maximum one band were considered as indistinguishable patterns.

For veterinary isolates, we reviewed all events of contamination of animals and food items by $S$. Goldcoast reported at the national level during 2009. These events are detected as part of routine surveillance through serotyping of Salmonella isolates at the Veterinary Salmonella Reference Laboratory in order to monitor the incidence of $S$. Enteritidis, $S$. Typhimurium and other serotypes in the framework of the EU Directive 2003/99/EC [13].

\section{Analytical epidemiology}

The epidemiologists at NCE conducted explorative telephone interviews in Hungarian with the 16 cases identified between 9 October and 14 November 2009 (the time when the unusual increase was observed). For this purpose, a standardised trawling questionnaire was used in order to generate hypotheses on which consumed food items could pose a risk of infection with S. Goldcoast. The questionnaire collected demographic information and details on food items, including typical Hungarian dishes and foods, consumed in the seven days before symptom onset.

A matched case-control study was conducted to identify those of the food items mentioned in the trawling questionnaire for which consumption was associated with becoming a $S$. Goldcoast case in Hungary after 1 October 2009. A case was defined as a person of any age resident in Hungary and registered either in the national database of notifiable diseases or the electronic database of mandatory notification of the regional laboratories with laboratory-confirmed infection by $S$. Goldcoast since 1 October 2009. This time period was chosen in order to reduce the problems of recall in the epidemiological interviews which only started during December 2009. Cases who had been interviewed using the trawling questionnaire were also included in this study.

A control was defined as a person within five years of the matched case's age who resided in the same administrative region as a case. Controls were not to have experienced any of the following gastrointestinal symptoms during one month before the interview: either diarrhoea (three or more loose stools per day) or vomiting. Controls were randomly selected from the national database of notifiable diseases and the electronic database of mandatory notification of the regional laboratories among those reported for any disease other than gastroenteritis in the two-week period from one week before to one week after the onset of symptoms of their matched case.

For the sample size calculation we assumed that $70 \%$ of the Hungarian population consumed pork-containing food products at least several times a week [6]. We sought two controls per case and calculated that
FIGURE 1

Notified Salmonella Goldcoast cases by age group, Hungary, January 2009-March 2010 (n=60)

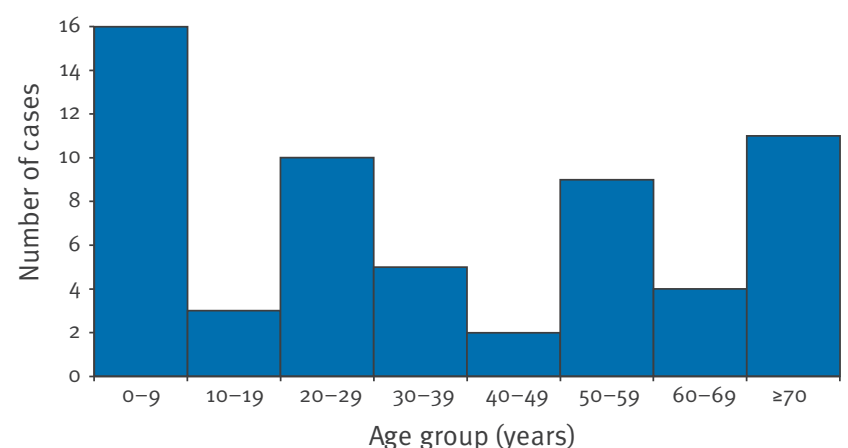

a sample size of 44 cases and 88 controls (2:1) would have $80 \%$ power to detect a minimum significant odds ratio (OR) of 5.0 with exposure in controls of $70 \%$.

The questionnaire used for interviews of cases and controls was specifically designed for this investigation in Hungary and adapted from the trawling questionnaire; and contained questions about demographics, clinical symptoms, laboratory examinations, travel history and the history of consumption of the food items most frequently mentioned in the trawling questionnaire in the seven days before getting sick (for cases) and before the interview (for controls). This also included questions about the way the food item had been prepared (consumed raw, insufficiently heated or well heated) and whether the product was homemade, locally produced or a commercial product. Questions about cheese as a possible risk factor were discarded for the case-control questionnaire as the majority of cheeses consumed by the respondents to the trawling questionnaire were produced by only a few manufacturers and commercially distributed in large numbers nationwide. Interviews with cases and controls were conducted by telephone by the Department of Communicable Disease Epidemiology at the NCE in Hungary.

The proportion of cases who consumed certain food items was compared with the proportion of their matched controls for the same exposure. Matched odds ratios and their respective $95 \%$ confidence intervals $(\mathrm{Cl})$ and $\mathrm{p}$ values were calculated for each exposure and food item using the Mantel-Haenszel method. Sensitivity analysis was conducted to take into account any potential cluster effect. Conditional logistic regression was used for multivariable analysis. The null hypotheses were tested at the 0.05 significance level. Data analysis was done using STATA version 10. 


\section{FIGURE 2}

Notified Salmonella Goldcoast cases (only symptomatic) by week of onset, Hungary, January 2009-March 2010 ( $\mathrm{n}=57$ )

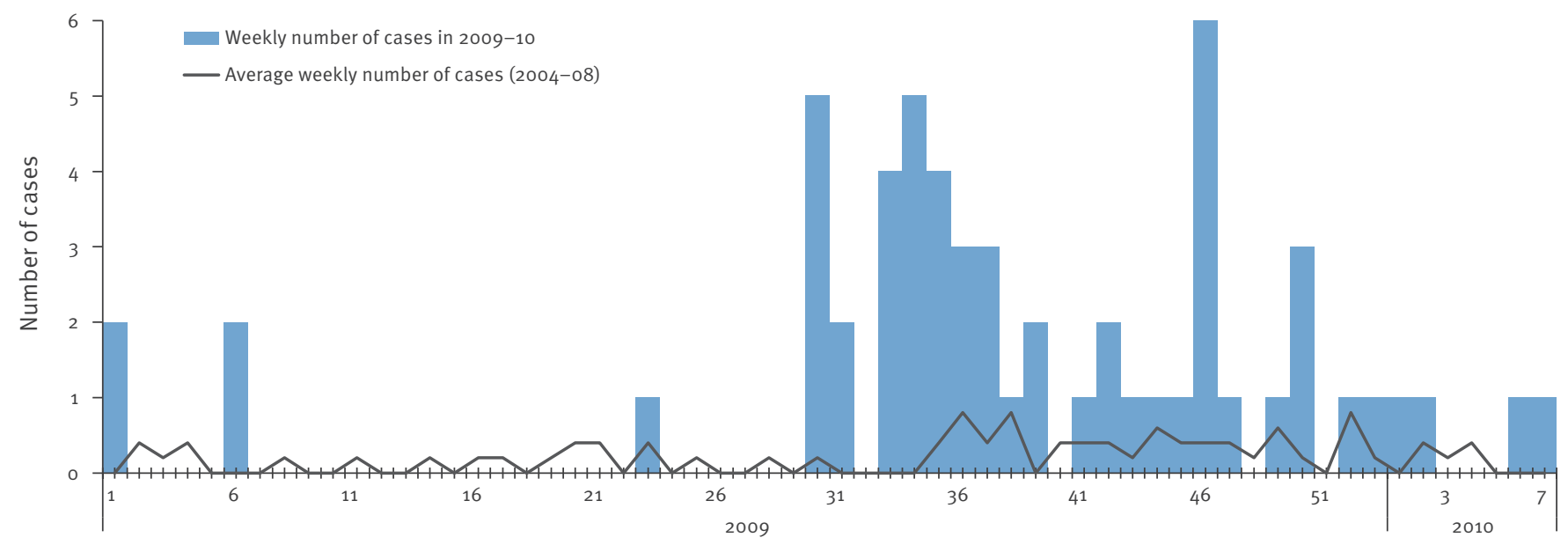

Week of onset

Date of onset of symptoms was not available for three cases.

\section{FIGURE 3}

Distribution of Salmonella Goldcoast cases, Hungary, January 2009-March 2010 (n=60)

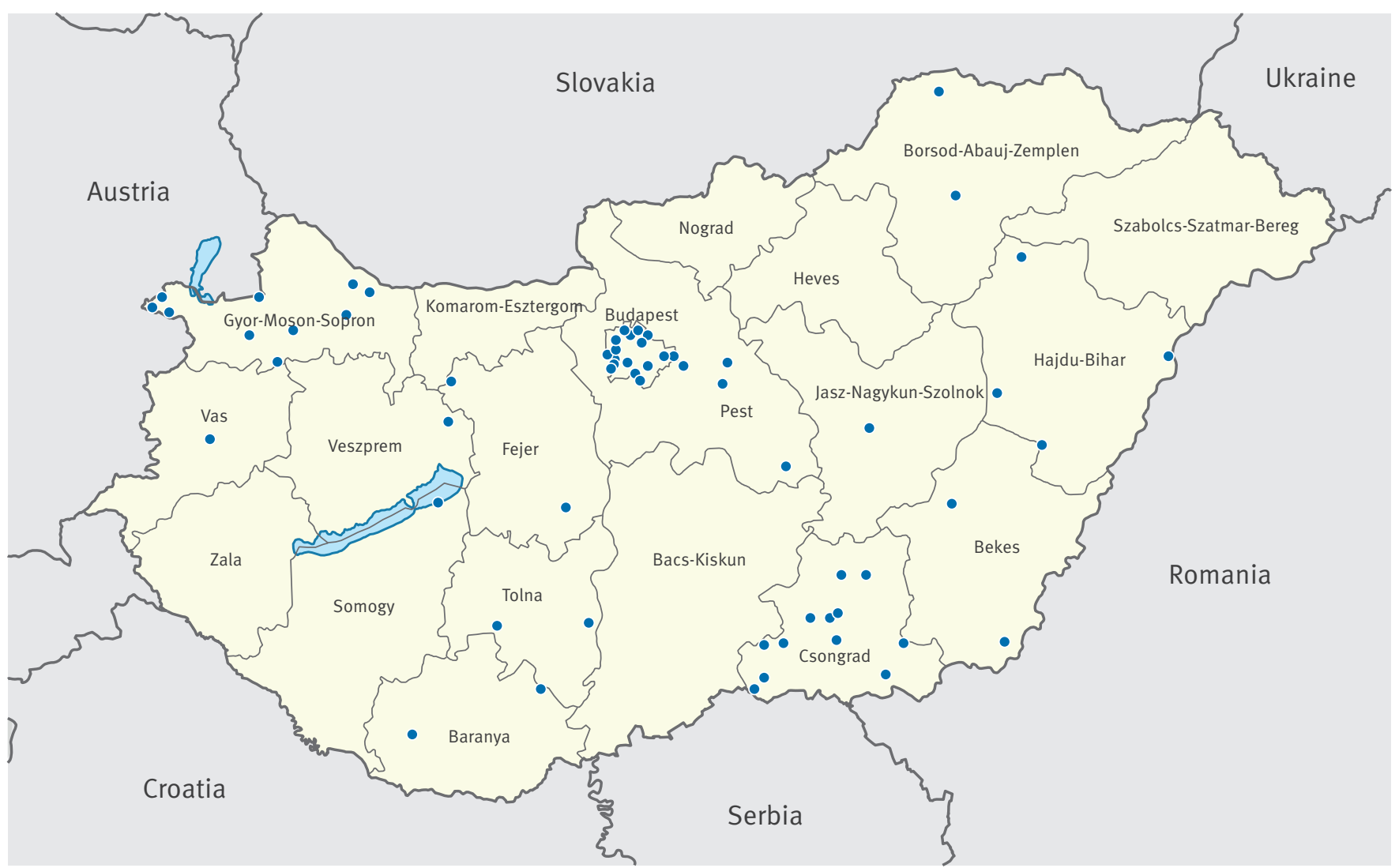




\section{Results}

\section{Descriptive epidemiology}

\section{Identified cases}

A total of 60 cases of $S$. Goldcoast were notified between 1 January 2009 and 1 March 2010 in Hungary. Thirty-four of these cases were male, and 16 were children under the age of 10 years (Figure 1). The majority of them, 50 cases, occurred from late July 2009 to January 2010; five cases occurred before week 30 in 2009, and two cases after week 2 in 2010 (Figure 2). Cases were distributed widely throughout the whole country [14]. All seven regions of Hungary were affected (Figure 3 ). The majority of cases $(n=16)$ occurred in the capital city, Budapest. The incidence (cases/per 100,000 population) was two to four times higher than the national average $(0.6 / 100,000)$ in three counties (Csongrád: 2.6, Györ-Moson-Sopron: 2.2, and Tolna: 1.3). None of the cases reported international travel before becoming ill.

Seven of 10 cases that occurred in November 2009 were part of a family cluster from two cities in southern Hungary. The investigation by the local health authorities revealed that they had bought pork meat, pork lard, pork internal organs and pig's head from different local supermarkets between late October and early November to prepare sausage, black pudding (blood sausage) and pork cheese (known as disznósajt in Hungarian). Pork cheese is a special type of Hungarian food that consists of cooked pig's organs and meat, stuffed into a pig's stomach. The family consumed the home-made pork cheese on a day in mid-November (except for one case who ate it on the following morning). The dates of onset of symptoms were between one and four days later. Two cases from this cluster were hospitalised. The family did not eat from the sausage and black pudding prepared at home before their onset of symptoms.

\section{Microbiological findings}

Laboratory investigation of $50 \mathrm{~S}$. Goldcoast isolates revealed that 35 of them were sensitive to all 12 antimicrobials used in the agreed EU surveillance panel. The majority $(n=44)$ of the isolates were indistinguishable by PFGE and belonged to the pattern named SCG $X b a^{3}$ (personal communication, Ida Luzzi, June 2010). The PFGE profiles for all seven cases from the family cluster also belonged to SGC $X b a^{3}$. Leftover food items from the household of the family cluster tested negative for Salmonella spp. contamination.

\section{Veterinary findings}

No increase in the occurrence of $S$. Goldcoast in any of the routinely investigated animals or animal products was observed during 2009 by the Hungarian Veterinary Authorities. The Hungarian Agriculture Office informed the National Public Health and Medical Officer Service that following routine meat inspection in 2009, only one of 5,000 tested samples was positive for
S. Goldcoast. The sample had been taken from minced beef sold in a butcher's shop located in Baranya county (South Transdanubian Region). The meat originated from a cow slaughtered in an abattoir which was used for slaughtering pigs as well.

\section{Analytical epidemiology}

Trawling questionnaire

Sixteen cases with dates of onset of disease between 9 October and 14 November were interviewed using the trawling questionnaire. They came from six different regions and their age ranged between two and 88 years (mean age: 52 years), the male/female ratio was $9 / 7$.

Fifteen cases reported frequent consumption of a variety of pork-containing items in the seven days before onset of symptoms. Furthermore, during this same exposure period, only two cases had consumed beef, which had been well cooked. The results from the trawling questionnaire along with the literature review suggested that pork-containing products were the potential risky food items transmitting $S$. Goldcoast.

\section{Case-control study}

Cases and controls: A total of 23 cases (mean age: 41 years; range: $0-88$ years) and 36 controls (mean age: 30 years; range: $0-75$ years) were identified to be eligible for the matched case-control study. The male/ female ratio was $13 / 10$. The reported dates of symptom onset were between 9 October 2009 and 16 February 2010. Four cases were discarded from the final analysis because no appropriate controls could be identified for them. Also, two controls were discarded after their matched case was not interviewed. Therefore a total of 19 cases and 34 controls were included in the statistical analysis.

Clinical presentation: The most frequent symptoms reported by the 23 interviewed cases were diarrhoea (the passage of three or more loose or liquid stools in a 24 hour period, 18 cases), abdominal cramps (10 cases), fever (10 cases) and fatigue (nine cases). Only two cases were hospitalised for their symptoms. No deaths occurred in the study population.

Food consumption history: The food items most frequently consumed by cases were pork chop (nine cases), pork cheese (nine cases) and salami (five cases). In the univariable analysis, a statistically significant association was only identified between $S$. Goldcoast infection and the consumption of pork cheese (Mantel-Haenszel odds ratio (MH OR): 11.29; 95\% Cl: 1.38-92.32). However, as noted above, the majority of cases (seven of nine) reporting consumption of this product pertained to a single family cluster. After removing the six cases of the family cluster, pork cheese still showed an elevated risk for being a case in the univariable analysis (MH OR: 3.87), but it was not significant $(p=0.25 ; 95 \% \mathrm{Cl}: 0.38-39.47)$. 
Matched univariable analysis of consumption of various pork food items, Salmonella Goldcoast case-control study, Hungary, January 2009-March $2010(\mathrm{n}=53)$

\begin{tabular}{|c|c|c|c|c|c|c|}
\hline \multirow{2}{*}{ Food item } & \multicolumn{2}{|c|}{ Cases $(n=19)$} & \multicolumn{2}{|c|}{ Controls $(n=34)$} & \multirow{2}{*}{$\begin{array}{c}\text { MH OR } \\
\text { (p value) }\end{array}$} & \multirow{2}{*}{$95 \% \mathrm{Cl}$} \\
\hline & Exposed & $\%$ & Exposed & $\%$ & & \\
\hline Pork cheese & 9 & 47.4 & 3 & 8.8 & $11.29(0.02)$ & $1.38-92.32$ \\
\hline Raw and other sausages & 4 & 21.1 & 3 & 8.8 & $1.51(0.60)$ & $0.31-7.17$ \\
\hline Salami & 5 & 33.4 & 9 & 26.5 & $1.08(0.91)$ & $0.29-3.93$ \\
\hline Liver paté & 1 & 8.4 & 4 & 12.1 & $1.00(1.00)$ & $0.09-11.03$ \\
\hline Liver sausage & 1 & 5.0 & 1 & 2.9 & $1.00(1.00)$ & $0.06-15.98$ \\
\hline Ham smoked & 1 & 7.1 & 3 & 8.3 & $0.67(0.73)$ & $0.07-6.40$ \\
\hline Smoked sausage & 3 & 20.0 & 12 & $35 \cdot 3$ & $0.65(0.60)$ & $0.13-3.16$ \\
\hline Pork crackling & 2 & 10.0 & 5 & $14 \cdot 7$ & $0.64(0.60)$ & $0.12-3.38$ \\
\hline Liver paste & 2 & 18.2 & 8 & 23.5 & $0.60(0.58)$ & $0.11-3.49$ \\
\hline Pork chop & 9 & $64 \cdot 3$ & 27 & $79 \cdot 4$ & $0.49(0.36)$ & $0.11-2.28$ \\
\hline Pork lard & 1 & $5 \cdot 9$ & 6 & $17 \cdot 7$ & $0.35(0.04)$ & $0.04-3.02$ \\
\hline
\end{tabular}

$\mathrm{Cl}$ : confidence interval; MH OR: Mantel-Haenszel odds ratio.

Only food items are listed for which discordant pairs of cases and controls could be formed for matched analysis.

'Other sausages' refer to sausages that are not totally raw but treated to some extent.

The food consumption frequencies by cases and controls are listed in the Table. The multivariable analysis using conditional logistic regression did not implicate any food item being independently associated with S. Goldcoast infection.

\section{Discussion}

S. Goldcoast is rarely identified as the implicated pathogen in persons with gastrointestinal disease in Hungary. Previous surveillance data has shown that on average 12 human cases were reported annually between 2004 and 2008. The increase in reported cases observed from July 2009 onwards was therefore noteworthy and merited further epidemiological and microbiological investigation.

Both our epidemiological and microbiological results suggest that the unusual increase in $S$. Goldcoast cases in Hungary between 1 January 2009 and 1 March 2010 was part of a national outbreak with multiple sources. The majority of the human S. Goldcoast isolates showed indistinguishable PFGE profiles and were sensitive to the same panel of antimicrobial drugs, which suggests that they belonged to the same bacterial clone and thus shared a common origin earlier in the food chain. None of the cases reported travel outside of Hungary in the days leading up to their illness, and therefore they had domestically acquired infections. Additionally, the country-wide distribution and the presence of confirmed cases in all age groups suggests that the potentially contaminated food ingredient was consumed by all groups of people and that it was available throughout the country. The higher number of reported cases from Budapest is simply a reflection of the population density in the capital city. As confirmed cases were reported over a period of 24 weeks, the presence of contaminated food items in the food chain was continuous for at least six months. A continuous source of contaminated food could point to a product with a long shelf life or to a source in animal populations (i.e. pigs or cattle) that carry the infection and may result in a prolonged introduction of contaminated meat into the retail market. Pork cheese, which was significantly associated with being a case in the univariable analysis, was probably identified because of the family cluster in which cases had consumed the food item together before developing disease symptoms. That pork cheese was prepared at home makes it possible that it was improperly cooked and/or became cross-contaminated. Unfortunately, the analyses were not able to implicate any food item being independently associated with $S$. Goldcoast infection due to the small sample size. However, the family outbreak suggested that pork-containing products were a likely source of infection. The sample from minced beef, which was found positive for $S$. Goldcoast in the veterinary surveillance, could have originated from a truly positive cow, but cross-contamination, either at the abattoir or at the butcher's shop, cannot be excluded since the meat originated from an abattoir where pigs were also slaughtered.

This outbreak investigation encountered several limitations which might explain the absence of concrete epidemiological evidence to identify the potential source(s) of infection for the $S$. Goldcoast cases in Hungary between 1 January 2009 and 1 March 2010. According to the epidemic curve, the peak of the unusual increase occurred between late July and September 2009. As this outbreak investigation only started in December 2009, the majority of the cases were not included in the matched case-control study. In addition, the cases 
that were included in the case-control study reported symptom onset as far back as the beginning of October 2009. They might therefore have been unable to recall all food items consumed and answer the questions accurately in the questionnaire. The small sample size (19 cases and 34 controls) reduced the actual power of the study to $55 \%$ to detect a minimum significant odds ratio of 5.0 with exposure in controls of $70 \%$. The sample size could not be increased further due to the matching control selection procedures and criteria as well as waning of the outbreak after March 2010. The lack of statistical power in the case-control study reduced our ability to identify clear risk factors.

The case-control questionnaire was exclusively focused on pork products based on explorative interviews and background published evidence. Other possible sources of contamination might have remained undetected. Cheese as a possible risk factor was discarded assuming that the outbreak would have been much larger if the common source of $S$. Goldcoast infection had been a widely distributed commercial cheese product. Also, certain exposures which have been identified as potential confounders in previous studies, such as drinking alcohol during the meal, were not included in the questionnaire and therefore were not controlled for in the final analysis of the data [15].

We continue to believe that the national outbreak of S. Goldcoast in Hungary in 2009 and early 2010 was likely to be related to the consumption of pork meatcontaining products due to the following reasons. Firstly, two earlier large outbreaks of $S$. Goldcoast outbreaks in the EU were due to pork-containing products (fermented sausage and minced pork) $[16,17]$. Secondly, the results from the investigation of a simultaneous unusual increase in $S$. Goldcoast cases in Italy in 2009 suggested that the consumption of porkcontaining food, in particular salami could have been a potential risk factor for becoming a case [8]. Thirdly, the results from the trawling questionnaire with the Hungarian cases showed that most cases (except one) had consumed pork meat products and very few other meat products in the seven days before their disease onset. Finally, recent data from Salmonella surveys in pig holdings throughout the EU suggest that $S$. Goldcoast is one of the most common serotypes identified in pig breeding and production holdings outside Hungary [18]. This last piece of information allows us to hypothesise that, rather than a single contaminated food item, pigs from a number of holdings were contaminated, partly exported to other countries where they were raised and slaughtered and released to the national markets during several months. Fusce eget velit sapien. Donec et eros diam.

\section{Acknowledgements}

Field epidemiologists of regional and local levels of the National Public Health and Medical Officer Service (Hungary) and Hungarian Veterinary Authorities for their contribution to the study. Fernando Simon and Alicia Barrasa (National Centre for Epidemiology, Madrid, Spain) for critical review of the study protocol and the results. Celine Gossner (ECDC, Stockholm, Sweden) for the preparation of the map.

References

1. Threlfall EJ, Hall ML, Rowe B. Salmonella Goldcoast from outbreaks of food-poisoning in the British Isles can be differentiated by plasmid profiles. J Hyg (Lond). 1986;97(1):11522. http://dx.doi.org/10.1017/So022172400064408

2. Joce R, O'Sullivan D, Strong C, Rowe B, Hall ML, Threlfall EJ. A national outbreak of Salmonella Gold-coast. Commun Dis Rep CDR Rev. 1990;4:3-4.

3. Salmonella Gold-coast and cheddar cheese: update. Commun Dis Rep CDR Wkly. 1997;7(11):93,96.

4. Salmonella Gold-coast. Commun Dis Rep CDR Wkly. 1996 Dec 20;6(51):443.

5. Coia J, Cormican M, Ethelberg S, Fisher I, Hernandez Pezzi G, Hjertqvist M, et al. Outbreak of Salmonella Goldcoast affecting tourists exposed in Majorca from the UK, Ireland, Sweden, Norway and Denmark. Euro Surveill. 2005;10(43): pii=2821. Available from: http://www.eurosurveillance.org/ViewArticle. aspx?Articleld $=2821$

6. Outbreak control team. Outbreak update: Salmonella Goldcoast infections in tourists returning from Majorca. Euro Surveill. 2005;10(44) $\mathrm{ii}=2826$. Available from: http://www. eurosurveillance.org/ViewArticle.aspx?Articleld=2826

7. Lewis H. International outbreak of Salmonella Goldcoast infection in tourists returning from Majorca, September-October 2005: final summary. Euro Surveill. 2005;10(49): pii=2853. Available from: http://www. eurosurveillance.org/ViewArticle.aspx?Articleld $=2853$. PMid:16794290.

8. Article about the national outbreak investigation in Italy in relation to the unusual increase of human cases of Salmonella Goldcoast (manuscript submitted to Eurosurveillance by Gaia Scavia)

9. Kahlmeter G, Brown DF, Goldstein FW, MacGowan AP, Mouton JW, Osterlund A, et al. European harmonization of MIC breakpoints for antimicrobial susceptibility testing of bacteria. J Antimicrob Chemother. 2003;52(2):145-8. http://dx.doi. org/10.1093/jac/dkg312. PMid:12837738.

10. Ribot EM, Fair MA, Gautom R, Cameron DN, Hunter SB, Swaminathan B, et al. Standardization of pulsed-field gel electrophoresis protocols for the subtyping of Escherichia coli 0157:H7, Salmonella, and Shigella for PulseNet. Foodborne Pathog Dis. 2006;3(1):59-67. http://dx.doi.org/10.1089/ fpd.2006.3.59. PMid:16602980.

11. Römling U, Tümmler B. Achieving $100 \%$ typeability of Pseudomonas aeruginosa by pulsed-field gel electrophoresis. J Clin Microbiol. 2000;38(1):464-5. PMid:10618146 PMCid:88754

12. Hunter SB, Vauterin P, Lambert-Fair MA, Van Duyne MS, Kubota $\mathrm{K}$, Graves L, et al. Establishment of a universal size standard strain for use with the PulseNet standardized pulsed-field ge electrophoresis protocols: converting the national databases to the new size standard. J Clin Microbiol. 2005;43(3):104550. http://dx.doi.org/10.1128/JCM.43.3.1045-1050.2005. PMid:15750058 PMCid:1081233.

13. DIRECTIVE 2003/99/EC OF THE EUROPEAN PARLIAMENT AND OF THE COUNCIL of 17 November 2003 on the monitoring of zoonoses and zoonotic agents, amending Council Decision 90/424/EEC and repealing Council Directive 92/117/EEC. 2003. Available from: http://eur-lex.europa.eu/LexUriServ/ LexUriServ.do?uri=0J:L:2003:325:0031:0040:EN:PDF

14. National Center for Epidemiology (NCE). Magyarország 2009. évi járványügyi helyzete [Annual Epidemiological report 2009]. Epinfo. 2011;7. Special issue. Hungarian. Available from: http://www.oek.hu/oek.web?to=,839,1890\&nid=964\&pid=1\& lang=hun

15. Bellido-Blasco JB, Arnedo-Pena A, Cordero-Cutillas E, CanosCabedo M, Herrero-Carot C, Safont-Adsuara L. The protective effect of alcoholic beverages on the occurrence of a Salmonella food-borne outbreak. Epidemiology. 2002;13(2):228-30. http://dx.doi.org/10.1097/00001648-200203000-00020. PMid:11880766.

16. Bremer V, Leitmeyer K, Jensen E, Metzel U, Meczulat H, Weise E, et al. Outbreak of Salmonella Goldcoast infections linked to consumption of fermented sausage, Germany 2001. Epidemiol Infect. 2004;132(5):881-7. http://dx.doi.org/10.1017/ S0950268804002699. PMid:15473151 PMCid:2870175.

17. Jansen A, Frank C, Stark K. Schweinefleisch und Schweinefleischprodukte als Quelle für humane Salmonellosen 
in Deutschland. [Pork and pork products as a source for human salmonellosis in Germany]. Berl Münch Tierärztl

Wochenschr. 2007;120(Heft 7/8): 340-346. German. Available from: http://vetline.de/facharchiv/veterinary_public_health/ bmtw/16739278.htm

18. European Food Safety Agency (EFSA). Analysis of the baseline survey on the prevalence of Salmonella in holdings with breeding pigs in the EU; 2008. EFSA Journal 2009; 7(12):1377. Available from: http://www.efsa.europa.eu/fr/scdocs/ doc/1377.pdf 